\title{
Effects of agitation level on the adsorption, desorption, and activities on cotton fabrics of full length and core domains of EGV (Humicola insolens) and CenA (Cellulomonas fimi)
}

\author{
Helena Azevedo ${ }^{\mathrm{a}, \mathrm{b}}$, David Bishop ${ }^{\mathrm{a}}$, Artur Cavaco-Paulo ${ }^{\mathrm{b}, *}$ \\ ${ }^{a}$ Department of Textile Design and Production, De Montfort University, Leicester LE1 9BH, United Kingdom \\ ${ }^{\mathrm{b}}$ Department of Textile Engineering, University of Minho, 4800 Guimarães, Portugal
}

Received 22 December 1999; received in revised form 1 March 2000; accepted 15 March 2000

\begin{abstract}
The activities (at $\mathrm{pH} 7$ and $50^{\circ} \mathrm{C}$ ) of purified $\mathrm{EGV}$ (Humicola insolens) and CenA (Cellulomonas fimi) were determined on cotton fabrics at high and low levels of mechanical agitation. Similar activity measurements were also made by using the core domains of these cellulases. Activity experiments suggested that the presence of cellulose binding domains (CBDs) is not essential for cellulase performance in the textile processes, where high levels of mechanical agitation are applied. The binding reversibilities of these cellulases and their cores were studied by dilution of the treatment liquor after equilibrium adsorption. EGV showed low percentage of adsorption under both levels of agitation. It was observed that the adsorption/desorption processes of cellulases are enhanced by higher mechanical agitation levels and that the binding of cellulase with CBD of family I (EGV) is more reversible than that of CBD of the cellulase of family II (CenA). (C) 2000 Elsevier Science Inc. All rights reserved.
\end{abstract}

Keywords: Cellulase adsorption; Cellulose binding domains (CBD); Mechanical agitation; Cellulase activities

\section{Introduction}

Most cellulases, like many others enzymes involved in the hydrolysis of insoluble polysaccharides, have a structure in which two distinct domains are connected by a linker peptide [1-3]. One of these domains seems to be involved mainly in substrate adsorption and is known as the cellulose binding domain (CBD). The other domain is the catalytic domain or core, which contains the amino acid sequences involved in the catalytic hydrolysis of $1,4-\beta$ glycosidic bonds.

The CBDs of cellulases have been grouped into several families based on similarities in their amino acid sequence [4]. Family I represents the smallest CBDs containing 33-36 amino acid residues; these occur only in fungal cellulases such as those secreted by Trichoderma reesei and Humicola insolens [5]. The CBDs of bacterial cellulases are larger, varying from 63-240 residues [2]. Family II CBDs

\footnotetext{
* Corresponding author. Tel.: +351-253-510280; fax: +351-253510293.

E-mail: artur@eng.uminho.pt (A. Cavaco-Paulo).
}

have about 110 amino acid residues and these include the CBDs of some cellulases of Cellulomonas fimi and Thermomonospora fusca [6].

The role of the CBD in cellulase activity is not well understood. Some authors $[3,4]$ have suggested that adsorption of the CBDs increases the concentration of the catalytic domains near the substrate, thereby increasing hydrolytic activity. Because the catalytic domain must also be adsorbed for hydrolysis to occur, the need for CBD adsorption is not clear.

By using techniques of genetic manipulation, it is possible to produce cellulases without CBDs. Alternatively, specific proteases may be used to hydrolyze the peptide linker to give separate CBDs and catalytic cores. These methods have enabled many studies designed to elucidate the mechanisms of degradation of crystalline cellulose by different cellulases [1,2]. Boraston et al. [4] have shown that family II CBDs disrupt the surface of cellulosic fibers and release fine particles from cotton or Avicel. CBDs of family I, however, have not been found to disrupt the cellulose structure.

The enzymatic hydrolysis of cellulose is a complex het- 
erogeneous reaction, with soluble cellulolytic enzymes converting solid cellulose into soluble sugars. The first step in this reaction is the adsorption of cellulases onto the surface of the cellulosic substrate. The reversibility of this initial step must be well understood because many applications of cellulases depend on the possibility of enzyme recycling. Jervis et al. [1] concluded that CBDs of bacterial cellulases from C. fimi (CenA and Cex CBDs, family II) bind irreversibly to crystalline cellulose because desorption of these CBDs was not observed after dilution [1,2]. Boraston et al. [4] found similar results with Cex CBD, and Bothwell et al. [7] reported irreversible adsorption for the endoglucanases E3 and E5 from T. fusca (CBDs of family II), but found completely reversible binding for CBHI from $T$. reesei (family I CBD). The latter is consistent with the reversible binding of the isolated $\mathrm{CBD}$ of $\mathrm{CBHI}$ from $T$. reesei demonstrated by Linder and Teeri [3].

In recent years, the use of cellulases in the textile industry has been increasing and now represents the largest market for these enzymes [8]. The main applications are in stonewashing of denim garments and in defuzzing or depilling fabrics, with the aim of improving their appearance and color brightness. During these processes, strong mechanical agitation is normally provided, although in some applications relatively low agitation levels may be used [9]. The crystalline structure of the cotton substrate and the slow kinetics of enzymatic degradation allow improvement in fabric properties to be made without significant fiber damage.

Genetic engineering is a powerful means of developing new enzymes with more specific activities for producing special effects. This can lead to new applications of the engineered cellulases in many areas, including textile processing. In the present work, two purified endoglucanases [EGV (EC 3.2.1.4) from H. insolens and CenA (EC 3.2.1.4) from $C$. fimi] were used for the hydrolysis of cotton fabrics at different levels of mechanical agitation to observe the influence of agitation on the processing of textile material with cellulases having CBDs of different families. The same experiments were also carried out with the isolated enzyme cores in an attempt to clarify the roles of the CBDs.

Adsorption/desorption studies were also made to observe the binding reversibilities of cellulases belonging to CBD families I and II.

\section{Materials and methods}

\subsection{Enzymes and substrate}

EGV (EC 3.2.1.4) from H. insolens and its isolated core were supplied as purified preparations by Novo-Nordisk (Bagsvagrd, Denmark). CenA (EC 3.2.1.4) from C. fimi and its core were supplied as purified preparations by University of British Columbia (Vancouver, B.C., Canada).

The substrate used in all experiments was scoured and bleached 100\% cotton poplin fabric having 60/32 ends/ picks $\mathrm{cm}^{-1}$ and area density of $100 \mathrm{~g}^{-2}$.

\subsection{Enzymatic treatments}

Fabric samples ( $3.5 \mathrm{~g})$ were incubated with each enzyme in phosphate buffer $(0.1 \mathrm{M}, \mathrm{pH} 7.0)$ at $50^{\circ} \mathrm{C}$, using a fabric to liquor ratio of $1: 10$. The enzyme dosage used was $1.5 \mathrm{mg}$ of protein/g of fabric in all experiments.

In low mechanical agitation experiments, the incubation time was $24 \mathrm{~h}$ in flasks held in a shaker bath operating at 125 strokes $\min ^{-1}$.

The high level of agitation was achieved by adding five stainless steel discs (each disc with average weight of $19.1 \mathrm{~g}, 32 \mathrm{~mm} \times 3 \mathrm{~mm}$ ) to the reaction mixture contained in 500-ml stainless steel pots of a Rotawash machine, rotating at $40 \mathrm{rev} . / \mathrm{min}$. The incubation time was $1 \mathrm{~h}$. For both agitation levels, control tests (identical treatments but without enzymes) were made to discount any weight loss caused by agitation in buffer only.

At the end of the treatments, the fabrics were removed from the liquor and rinsed with sodium carbonate $(5 \% \mathrm{w} / \mathrm{v})$ to stop the enzymatic reaction, washed thoroughly with hot and cold water, dried at room temperature, and conditioned $\left(20^{\circ} \mathrm{C}\right.$ and $65 \%$ relative humidity, $\left.24 \mathrm{~h}\right)$ before weighing for total weight-loss determination.

Two independent experiments were done for each treatment, and the results (shown in Figs. 2 and 3) represent the mean of these determinations.

\subsection{Adsorption/desorption studies}

For these studies, the same conditions described above were followed, using $5 \mathrm{~g}$ of fabric in $50 \mathrm{ml}$ of phosphate buffer. After the first incubation period ( $1 \mathrm{~h}$ and $24 \mathrm{~h}$ for the high and low agitation, respectively), the protein in solution was measured (see below) to calculate the percentage adsorption. The treatment liquor was then diluted (1:2) with phosphate buffer and the mixture was incubated for a further $30 \mathrm{~min}$ in the same agitation conditions. The concentration of protein in solution was measured.

A typical adsorption/desorption process is represented in Fig. 1. This shows that the free protein concentration returns to a new equilibrium after it has been disturbed by dilution with buffer, demonstrating that the binding of the protein is reversible. The percentage of adsorption and desorption was calculated by the following expressions:

$$
\begin{aligned}
& \% \text { adsorption }=\frac{A-B}{A} \times 100 \\
& \% \text { desorption }=\frac{D-C}{A} \times 100
\end{aligned}
$$




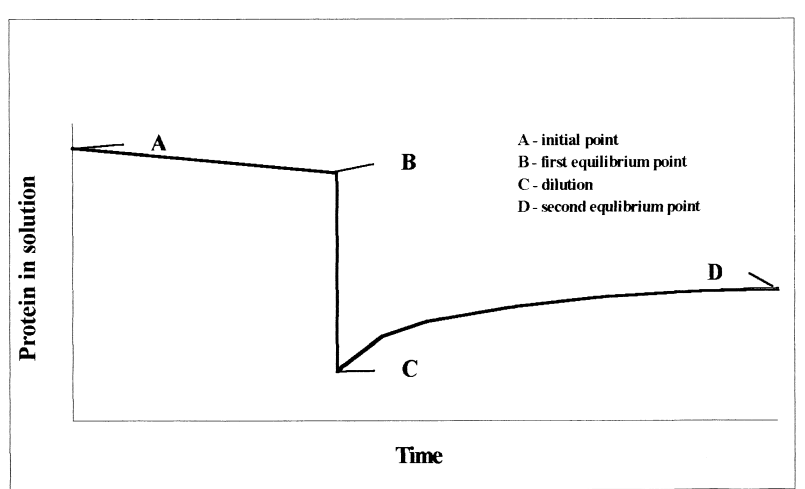

Fig. 1. Typical adsorption/desorption curve of a protein that binds reversibly.

\subsection{Determination of enzymatic activity on scoured cotton fabrics}

Enzymatic activity was measured in terms of fabric weight loss. Total weight loss was calculated by difference between fabric weights before and after treatment.

Insoluble weight loss was measured by using a strong oxidant (potassium dichromate) to digest insoluble material produced during hydrolysis. A sample of liquor was taken and centrifuged. The supernatant was removed, and the residue was washed with two portions of distilled water to remove all soluble sugars. The residue was dried overnight at $103 \pm 2{ }^{\circ} \mathrm{C}$. Two $\mathrm{ml}$ of $1.8 \%$ of potassium dichromate in sulfuric acid $(50 \%)$ reagent was added, mixed with the residue, and heated on a boiling water bath for $30 \mathrm{~min}$. After dilution with $50 \mathrm{ml}$ of distilled water, the absorbance of the solutions was read in a UV-Vis spectrophotometer against a water blank at $441 \mathrm{~nm}$. Glucose was used as a standard.

Soluble weight loss was determined by subtracting the value of insoluble weight loss from the total weight loss. Two replicates were made for each sample analysis.

\subsection{Determination of protein in solution}

Total protein in solution was measured by the Bradford assay [10], with BSA as standard. For each sample, three determinations were made.

\subsection{Determination of the cotton reducing power}

The reducing power, or end group content of fabric samples after enzymatic treatment, was determined by the method described by Cavaco-Paulo [9], which depends on the complex formed between neocuproin and reducing groups in the fiber. Three analyses were done for each fabric sample.
Table 1

Values of percentage of protein $( \pm$ maximum error in protein determination) adsorbed and desorbed after dilution with buffer (1:2) for the four proteins, using high level of mechanical agitation (Rotawash machine, 5 discs, $40 \mathrm{rpm}, 50^{\circ} \mathrm{C}$ ) and low level of mechanical agitation (Shaker bath, $125 \mathrm{rpm}, 50^{\circ} \mathrm{C}$ )

\begin{tabular}{lll}
\hline Protein & Rotawash & Shaker \\
\hline EGV & & \\
Adsorbed & $2 \pm 4$ & 0 \\
Desorbed & $2 \pm 1$ & - \\
EGV core & $2 \pm 4$ & 0 \\
Adsorbed & $2 \pm 1$ & - \\
Desorbed & $78 \pm 4$ & \\
CenA & $21 \pm 1$ & $47 \pm 4$ \\
Adsorbed & & $17 \pm 1$ \\
Desorbed & $27 \pm 4$ & $45 \pm 4$ \\
CenA core & $27 \pm 1$ & $5 \pm 1$ \\
Adsorbed & & \\
Desorbed & & \\
\hline
\end{tabular}

\section{Results and discussion}

\subsection{Adsorption/desorption studies}

The results of the adsorption/desorption studies, given in Table 1, show that the adsorption of EGV and EGV core was very low for both levels of agitation. This suggests that the action of this endoglucanase (with or without its family I CBD) may be achieved via rapid adsorption/desorption and that its binding to cotton cellulose is highly reversible. This tends to be confirmed by the fact that, after dilution, all protein was desorbed from the fabric, despite the low levels or absence of adsorption after the first period of incubation.

Transmission electron microscopy of the cross-section of cotton fibers treated with EGV enzyme immunogold labeled revealed that the EGV only binds to the surface and hydrolyses the amorphous cellulose on the surface, because no gold particles could be detected in the interior of the fiber [11]. This is an indicator that most cellulases only act on cellulose surface and do not penetrate inside the fibers.

For the CenA enzyme, much higher percentage of adsorption were observed at both agitation levels, 78 and $47 \%$ for high and low levels of agitation, respectively. Without the CBD, CenA core showed less percentage, 27 and $45 \%$, respectively, at high and low levels of agitation.

After dilution and reequilibration, about 21 and $17 \%$ of the CenA was desorbed at high and low levels of agitation, respectively, whereas CenA core presents 27 and 5\% of desorption. Thus, the cellulolytic action of CenA seems to be achieved via high levels of adsorption with low reversibility. CenA core shows completely reversibility adsorption on cotton cellulose at high level of mechanical agitation, but, at low level of agitation, low degree of desorption was verified. These results show that non-target proteins (cores) are just removed from the substrate with high mechanical agitation, whereas target proteins (with a family II 


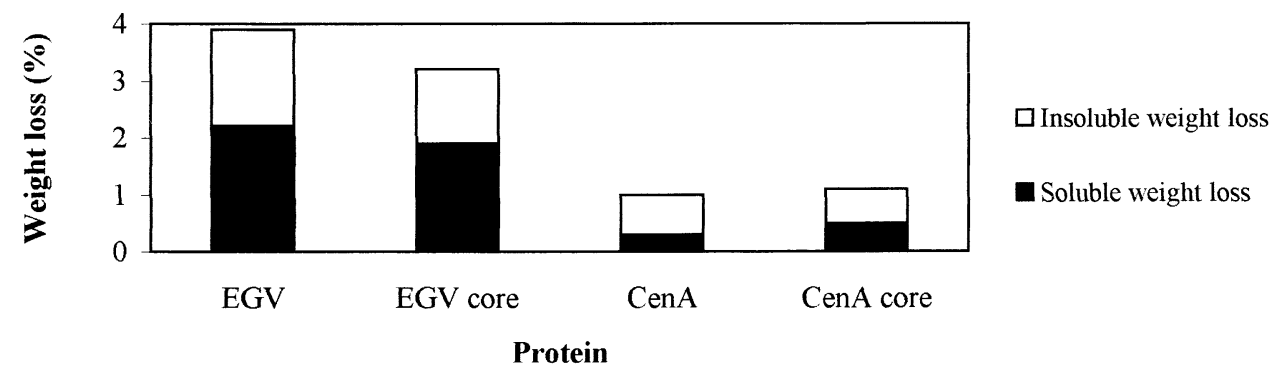

Fig. 2. Total (soluble and insoluble) fabric weight loss using high agitation level treatment (Rotawash machine, $1 \mathrm{~h}, 50^{\circ} \mathrm{C}, 5 \mathrm{discs}, 40 \mathrm{rev} . / \mathrm{min}, 1.5 \mathrm{mg}$ protein/g fabric in phosphate buffer, $\mathrm{pH}$ 7).

CBD) remain adsorbed even at high levels of agitation. It has been reported that CenA enzyme binds rapidly and tightly to cellulose and no net desorption of the protein was observed [1,12].

Others authors have shown [13] in desorption experiments with the isolated CBD of CenA (family II CBD) on cotton fabrics that at low mechanical agitation, little desorption occurred, but, at a higher degree of agitation and also at higher pHs, more protein was desorbed.

\subsection{Enzymatic treatments}

From Fig. 2 it can be seen that EGV and EGV core achieve three to four times the fabric weight loss produced by CenA and CenA core under the same high-agitation conditions. Although endoglucanases from different sources are expected to have different specific activities (catalytic domain of EGV H. insolens belongs to family 45 and CenA catalytic domain belongs to family 6 [6]), it is reasonable to suggest that these differences could result mainly from their different adsorption/desorption characteristics. It was reported that CenA only has moderate activity on crystalline cellulose, suggesting that the surface diffusion of CBDs does not limit substrate catalysis [1].

The highly reversible binding of EGV and EGV core may be the main reason for cleavage of more $1,4-\beta$-glucosidic bonds per minute than is achieved by the less mobile CenA and CenA core enzymes. Comparing the activity results of EGV and EGV core (Figs. 2 and 3), it is possible to notice that for high level of agitation, the enzymes show

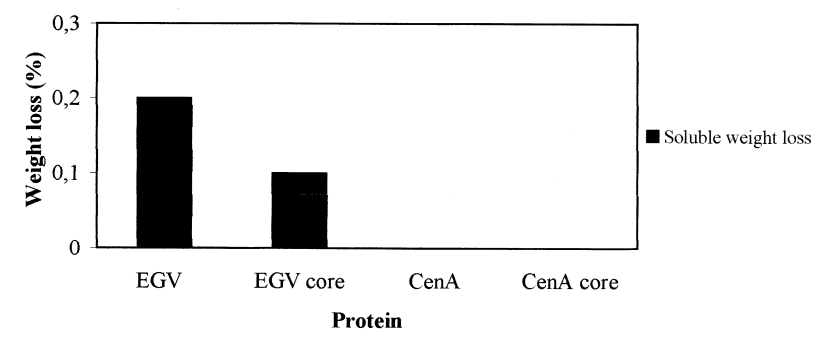

Fig. 3. Total fabric weight loss using low agitation level treatment (Shaker bath, $24 \mathrm{~h}, 50^{\circ} \mathrm{C}, 125 \mathrm{rev} . / \mathrm{min}, 1.5 \mathrm{mg}$ protein/g fabric in phosphate buffer, $\mathrm{pH}$ 7). similar activities. In low level of agitation, the soluble weight loss produced by EGV core is half of that obtained by the intact enzyme. This shows that the presence of CBD is not essential for the hydrolysis of cotton cellulose, even with less agitation.

Hydrolysis experiments made with CenA endoglucanase and its isolated catalytic domain on BMCC showed that, aside from the fact that no adsorption of the core was detected, the hydrolysis with the core was approximately $30 \%$ of that determined with an equimolar concentration of intact enzyme [12]. There are not significant differences on the activities of CenA and its core. It should be noted that it used an equal amount of protein, which did not correspond to an equal amount of protein in molar. In this case, there was higher molar concentration of CenA core present in the reaction mixture, which can be the reason for the similar results.

Comparing the levels of agitation (Figs. 2 and 3), it is evident that the mechanical agitation influences greatly the effect of the enzymes in the fibers, because the activity of both enzymes and their cores is drastically reduced on low level of mechanical agitation and only soluble sugars account for the weight loss achieved with EGV and its core, even with longer treatment. It is possible that the agitation level was not sufficient to break weakened microfibres processed by the cellulases and then there was no release of microfibre fragments in solution.

Mechanical abrasion has been indicated as to synergistically cooperate with endoglucanase activity. This is explained by the fact that mechanical agitation causes more fibrillation. In this situation, the loose fibrils (pills) formed represent an increased and more exposed specific surface area for enzyme attack. It was suggested that the pills would have lower crystallinity than the cellulose of the main fabric structure [11]. However, Morgado et al. [14] analyzed the crystallinity index of the pills produced by a primary fibrillation (washing of the fabrics at $40^{\circ} \mathrm{C}$, during $60 \mathrm{~min}$ in a jet with high mechanical agitation) and found that they did not show significant differences when compared with the cellulose of the main fabric structure.

In the case of CenA and CenA core, no weight loss was detected, but analysis for reducing groups in the fiber (Table 
Table 2

Reducing groups ( \pm maximum error) produced on the fibre by the CenA proteins at low agitation (Shaker bath, $125 \mathrm{rpm}, 50^{\circ} \mathrm{C}, 24 \mathrm{~h}, 1.5$ $\mathrm{mg}$ protein/g fabric in phosphate buffer $\mathrm{pH}$ 7)

\begin{tabular}{ll}
\hline Fabric treatment & $\begin{array}{l}\text { Reducing groups } \\
\text { (mg glucose/g cellulose) }\end{array}$ \\
\hline CenA & $0.29 \pm 0.01$ \\
CenA core & $0.34 \pm 0.02$ \\
Buffer only & $0.12 \pm 0.01$
\end{tabular}

2) shows that the greater mobility of the core again leads to slightly higher activity that the whole enzyme.

\section{Conclusions}

The results confirm previous findings [8] that agitation level has a profound effect on endoglucanase activity. In this work, it is clearly shown that the presence of CBDs is not essential to endoglucanase activity at high levels of mechanical agitation, similar to the process conditions used in the textile industry.

The highly reversible binding of EGV and EGV core proteins may be the main reason for their higher specific activity, compared with the more irreversibly bound CenA enzyme. Full-length CenA proteins just partially desorb, even at high levels of mechanical agitation where adsorption/desorption processes are enhanced.

The results shown here open new perspectives for applying separately either the hydrolytic activity or the disruptive properties (the core and $\mathrm{CBD}$, respectively) of these enzymes to treat textiles or other cellulosic materials.

\section{Acknowledgments}

We would like to thank Dr. Martin Schülein from NovoNordisk and Prof. Douglas Kilburn from the University of British Columbia for kindly supplying EGV and CenA proteins, respectively.

\section{References}

[1] Jervis EJ, Haynes CA, Kilburn DG. Surface diffusion of cellulases and their isolated binding domains on cellulose. J Biol Chem 1997; 272:24016-23.

[2] Henriksson G, Salumets A, Divne C, Pettersson G. Studies of cellulose binding by cellobiose dehydrogenase and a comparison with cellobiohydrolase I. Biochem J 1997;324:833-8.

[3] Linder M, Teeri TT. The cellulose-binding domain of the major cellobiohydrolase of Trichoderma reesei exhibits true reversibility and high exchange rate on crystalline cellulose. Proc Natl Acad Sci USA 1996;93:12251-5.

[4] Boraston A, Bray M, Brun E, et al. The structure and function of cellulose binding domains. In: Claeyssens M, Nerinckx W, Piens K, editors. Carbohydrates from Trichoderma reesei and other microorganisms. Cambridge, UK: The Royal Society of Chemistry, 1998. p. $139-46$.

[5] Tormo J, Lamed R, Chirino AJ, et al. Crystal structure of a bacterial family III cellulose-binding domain: a general mechanism for attachment to cellulose. EMBO J 1996;15:5739-51.

[6] Reinikainen T. The cellulose-binding domain of cellobiohydrolase I from Trichoderma reesei. Espoo, Finland: VTT Publications 206, 1994. PhD. Thesis.

[7] Bothwell MK, Wilson DB, Irwin DC, Walker LP. Binding reversibility and surface exchange of Thermomonospora fusca E3 and E5 and Trichoderma reesei CBHI. Enzyme Microb Technol 1997;20: 411-7.

[8] Cavaco-Paulo A. Mechanisms of cellulase action in textile processes. Carbohydr Polymers 1998;37:273-7.

[9] Cavaco-Paulo A, Almeida L, Bishop D. Effects of agitation and endoglucanase pretreatment on the hydrolysis of cotton fabrics by a total cellulase. Textile Res J 1996;66:287-94.

[10] Bradford MM. A rapid and sensitive method for the quantitation of microgram quantities of protein utilizing the principle of protein-dye binding. Anal Biochem 1976;72:248-55.

[11] Boisset C, Chanzy H, Schülein M, Henrissat B. An ultrastructural study of the interaction of fungal endoglucanase from Humicola insolens with cotton fibres. Cellulose 1997;4:7-20.

[12] Gilkes NR, Jervis E, Henrissat B, et al. The adsorption of a bacterial cellulase and its two isolated domains to crystalline cellulose. J Biol Chem 1992;267:6743-9.

[13] Cavaco-Paulo A, Morgado J, Andreaus J, Kilburn D. Interactions of cotton with CBD peptides. Enzyme Microb Technol 1999;25:63943.

[14] Morgado J, Cavaco-Paulo A, Roussele M-C. Enzymatic treatment of lyocell-clarification of depilling mechanisms. Textile Res J, In press. 